\title{
Suppression of p16 alleviates the senescence-associated secretory phenotype
}

\author{
Raquel Buj ${ }^{1 * \#}$, Kelly E. Leon ${ }^{1 \#}$, and Katherine M. Aird ${ }^{1 * \#}$ \\ ${ }^{1}$ Department of Cellular \& Molecular Physiology, Penn State College of Medicine, Hershey, PA, \\ USA
}

*Corresponding Authors

Raquel Buj

Postdoctoral Fellow

Department of Cellular \& Molecular Physiology

Penn State College of Medicine

500 University Dr., H166

Hershey, PA 17033

Tel: 7175310003 ext 282598

Fax: 7175317667

rbujgomez@pennstatehealth.psu.edu

and

Katherine M. Aird

Assistant Professor

Department of Cellular \& Molecular Physiology

Penn State College of Medicine

500 University Dr., H166

Hershey, PA 17033

Tel: 7175315014

Fax: 7175317667

kaird@psu.edu

\#New address as of September 1, 2020:

Hillman Cancer Center

Department of Pharmacology and Chemical Biology

University of Pittsburgh

5117 Centre Ave., 1.48

Pittsburgh, PA 15232

kaa140@pitt.edu

Keywords: Interleukin-6, interleukin-8, LMNB1, melanoma, colorectal adenocarcinoma, pancreatic adenocarcinoma 


\begin{abstract}
Oncogene induced senescence (OIS) is characterized by increased expression of the cell cycle inhibitor $\mathrm{p} 16$, leading to a hallmark cell cycle arrest. Suppression of $\mathrm{p} 16$ in this context drives proliferation, senescence bypass, and contributes to tumorigenesis. OIS cells are also characterized by the expression and secretion of a widely variable group of factors collectively termed the senescence-associated secretory phenotype (SASP). The SASP can be both beneficial and detrimental and affects the microenvironment in a highly context-dependent manner. The relationship between p16 suppression and the SASP remains unclear. Here, we show that knockdown of p16 decreases expression of the SASP factors and pro-inflammatory cytokines IL6 and CXCL8 in both RAS ${ }^{\mathrm{G} 12 \mathrm{~V}}$ - and $\mathrm{BRAF}^{\mathrm{V} 600 \mathrm{E}}$-induced senescence. Notably, this is likely not due to suppression of senescence as $L M N B 1$ and cyclin A expression remain low and p21 remains high. Moreover, low p16 expression in both cancer cell lines and patient samples correspond to decreased SASP gene expression, suggesting this is a universal effect of loss of p16 expression. Together, our data suggest that p16 transcriptionally regulates SASP gene expression, which has implications for understanding how p16 modulates both the senescent and tumor microenvironment.
\end{abstract}




\section{Introduction}

Senescence is considered a state of stable cell cycle arrest that can occur due to a variety of stimuli [1]. Oncogene-induced senescence (OIS) occurs upon activation of an oncogene such as HRAS or BRAF in normal cells [2, 3]. One of the hallmarks of senescent cells is upregulation of the cell cycle inhibitor CDKN2A (encoding for p16), which restrains cell cycle progression and cellular proliferation [4-6]. Canonically, elevated p16 represses hyperphosphorylation of the retinoblastoma protein $(\mathrm{RB})$, which inhibits $\mathrm{E} 2 \mathrm{~F}$ transcription factor-mediated expression of proliferative genes [7]. Loss of $\mathrm{p} 16$ is a common event in human cancer that has been linked to senescence bypass, increased proliferation, and malignant transformation though both canonical and non-canonical (RB-independent) pathways [8-12].

The acquisition of a senescence-associated secretory phenotype (SASP) is also characteristic of OIS cells [13]. The SASP is composed of a variety of soluble signaling factors including proinflammatory cytokines, chemokines, and growth factors, as well as proteases, insoluble extracellular matrix proteins and non-protein components that are transcriptionally and translationally upregulated and secreted into the surrounding microenvironment by senescent cells [14-18]. Due to the impact that SASP can exert on cellular physiology, this program is tightly regulated at multiple levels. At the transcriptional level, several transcription factors (NF-kB, C/EBP- $\beta$ ) and upstream regulators (p38 MAPK, GATA4, p53, and ATM) have been described to either positively or negatively regulate SASP gene expression [16, 19-25]. The SASP is also regulated at both the epigenetic [26-31] and translational level [17, 32]. Recent publications suggest that the initiation of SASP gene transcription during OIS is likely due to loss of lamin B1 (LMNB1) and nuclear integrity [33, 34], leading to the accumulation of cytoplasmic chromatin 
fragments (CCFs) $[35,36]$. CCFs activate the cytosolic DNA sensor cyclic guanosine monophosphate (GMP)-adenosine monophosphate (AMP) synthase (cGAS) that catalyzes the synthesis of the second messenger cyclic GMP-AMP (cGAMP) to bind and activate stimulator of interferon genes (STING), leading to NF-KB activation and cytokine transcription $[35,37,38]$. Therefore, changes in LMNB1 expression are tightly linked to SASP gene transcription.

It is well documented that the SASP modifies the cellular microenvironment and alters neighboring cells, exerting a pleiotropic effect that is not fully understood [39]. On one hand, SASP factors contribute to wound-healing [40-42], normal development [43, 44], and have tumor suppressive effects through the recruitment of different immune cells to clear premalignant cells, a process termed senescence surveillance [45-47]. On the other hand, SASP factors can be pro-tumorigenic by sustaining proliferation, invasion, metastasis, and chemoresistance [48-52]. This paradoxical double role of SASP factors is highly dependent on both genetic background and SASP composition, which is known to be both variable and dynamic [53]. Different genetic backgrounds, cellular contexts, and/or senescence inducers allow for different SASP programs that can promote or inhibit tumorigenesis [54-56]. Interestingly, different SASP programs can also induce senescence in neighboring cells in a paracrine manner that in turn express a particular SASP program [54]. Thus, the final beneficial or detrimental outcome net effect of the SASP is governed by multiple mechanisms that are not yet fully understood [57]. Characterizing whether different genetic backgrounds lead to different SASP programs may be critical to develop efficient and personalized regimens for cancer patients. As $\sim 50 \%$ of all human tumors have low $\mathrm{p} 16$ expression [58], understanding its role in regulating the SASP has implications for a large subset of patients. 
Here, we investigated the effect of $\mathrm{p} 16$ suppression on SASP gene expression. We found that knockdown of p16 leads to decreased IL6 and CXCL8 (encoding IL8) SASP gene expression in both HRAS ${ }^{\mathrm{G} 12 \mathrm{~V}}$ and BRAF ${ }^{\mathrm{V} 600 \mathrm{E}}$ models of OIS. This was not due to increased LMNB1 expression, indicating that these changes were not simply an artifact of reduced senescence or inhibited upstream signaling. We confirmed these results in p16-wildtype melanoma cells upon knockdown of p16. Moreover, using publicly-available data, we found that low CDKN2A expression in patient tumors is associated with a tumor-characteristic decrease in specific SASP programs. Together, our results suggest that p16 may have a role in transcriptionally regulating SASP factors, which has implications for understanding how loss of p16 affects the senescent and tumor microenvironment. 


\section{$\underline{\text { Results }}$}

\section{Knockdown of p16 abrogates oncogene-induced IL6 and CXCL8 expression}

Upregulation of both $\mathrm{p} 16$ and SASP factors are characteristic of OIS cells [13]. A previous study found that overexpression of p16 induces senescence without upregulation of the SASP [59]. However, it is unknown whether $\mathrm{p} 16$ upregulation is necessary for SASP gene expression in the context of OIS. In order to better understand the effects of p16 expression on the SASP, we assessed the expression of the most extensively characterized interleukins upregulated in senescence, IL6 and IL8 $[13,16,60]$. Concomitant knockdown of p16 with BRAF ${ }^{\mathrm{V} 600 \mathrm{E}}$ or HRAS $\mathrm{H}^{\mathrm{G} 12 \mathrm{~V}}$ overexpression decreased IL6 and CXCL8 expression in IMR90 fibroblasts (Fig. 1A-E), a classical model of OIS $[5,61]$. The shRNA hairpin specificity targeting p16 was previously validated [8]. Similar results were observed in normal skin fibroblasts Hs 895.Sk (Fig. 1F-G), suggesting this is not a cell line-specific phenomenon. Together, these data demonstrate that knockdown of p16 abrogates IL6 and CXCL8 expression due to oncogene activation.

We previously published that knockdown of p16 concomitantly with expression of BRAF ${ }^{\mathrm{V} 600 \mathrm{E}}$ bypasses senescence in IMR90 cells [8]. Therefore, it is possible that the SASP expression is low because the cells never undergo OIS. To investigate whether the observed decrease in IL6 and CXCL8 is a direct effect of $p 16$ suppression and not simply a consequence of senescence bypass, we knocked down p16 at different time points after oncogene expression (Fig. 2A). Consistent with our previous data, knockdown of p16 at these different timepoints also decreased both IL6 and CXCL8 expression (Fig. 2B-D). Notably, this was not due to a decrease in senescence as p21 remained high and cyclin A and $L M N B 1$ expression remained low (Fig. 2B \& 2E). These data suggest that $\mathrm{p} 16$ regulates IL6 and CXCL8 expression, which is uncoupled from senescence bypass. 


\section{Knockdown of p16 in tumor cells decreases IL6 and CXCL8 expression}

Next, we aimed to investigate whether suppression of p16 leads to decreased expression of IL6 and CXCL8 in tumor cells. Towards this goal, we knocked down p16 in three melanoma cell lines with wildtype p16 (Fig. 3A). Similar to normal fibroblasts, knockdown of p16 decreased both IL6 and CXCL8 in the melanoma cells (Fig. 3B-D). Consistent with our data in fibroblasts (Fig. 2), suppression of p16 in the melanoma cells also decreased IL6 and CXCL8 expression. Altogether, these data suggest that p16 transcriptionally regulates both IL6 and CXCL8 and support the hypothesis that this is not a consequence of $\mathrm{p} 16$ suppression-mediated senescence bypass since suppression of p16 in both OIS and proliferating melanoma cells abrogates IL6 and CXCL8.

\section{Low CDKN2A in patient tumors correlates with low SASP expression}

It has been widely demonstrated that suppression of $\mathrm{p} 16$ leads to increased proliferation, tumorigenesis, and metastasis in vitro and in vivo, and loss of p16 expression is considered a poor prognostic maker [62-65]. To further understand the relationship between loss of p16 and decreased expression of the SASP, we used TCGA data from skin cutaneous melanoma (SKCM, $\mathrm{n}=473$ ), pancreatic adenocarcinoma (PAAD, $n=183$ ), and colorectal adenocarcinoma (COADREAD, $n=82$ ), which are all in part characterized by loss of $p 16$ expression [66]. Patients were classified according to their CDKN2A status (p16 low or high, see Methods for details) (Table 1), and differential expression analysis was performed independently for each tumor type. Consistently with our previous findings, most of the SASP factors profiled upon RAS-induced senescence (including soluble factors and exosomes, 232 total unique genes) (Table S1) [53] were significantly downregulated in p16-low samples in all three tumor types (Fig. 4A and Table S2). Interestingly, only 4 SASP factors (HLA-A, TNIP2, ACTB, and TTYH3) were significantly 
downregulated in all 3 tumor types (Fig. 4B and Table S3), suggesting that although decreased expression of SASP factors is a characteristic of p16-low tumors, each tumor type displays a distinct profile. Consistent with this observation, Gene Set Enrichment Analysis (GSEA) revealed that pathways related to the SASP, inflammation, and the immune system such as: 'Senescence Associated Secretory Phenotype', "Antigen Processing Cross Presentation”, and “Cytosolic DNA Sensing Pathway" where negatively enriched (i.e., negative Normalized Enrichment Score, NES) in p16-low samples in all three tumor types (Fig. 4C and Table S4). These data suggest that p16 at least in part transcriptionally regulates SASP factors in human tumor samples. Finally, since we observed downregulation of the "Cytosolic DNA Sensing Pathway" signature, we correlated the expression level of $C D K N 2 A$ and $L M N B 1$ in the tumors. We did not observe a strong correlation between $C D K N 2 A$ and $L M N B 1$ expression (Fig. 4D), suggesting that p16 regulation of this pathway and the SASP in tumors is not through modulation of LMNB1. All together with our in vitro data, these data in human tumor samples demonstrate a universal, positive correlation between p16 expression and SASP gene expression. 


\section{Discussion}

Increased expression of p16 and SASP are characteristics of OIS; however, the relationship between them is not well understood. While increased p16 expression has a clear role in sustaining the characteristic cell cycle arrest of OIS cells [8,67], the SASP appears to be a consequence of the DNA damage response induced by OIS and is not necessary for the proliferative arrest $[24,68,69]$. Indeed, this is evident by the observation that p16-mediated senescence induction, a stimulus that a priori only restrains cell cycle progression, does not induce SASP expression [59]. Here we found that knockdown p16 decreases gene expression of two of the most well characterized SASP factors IL6 and CXCL8 $[13,16,60]$, while there was no concurrent increase in LMNB1 and cyclin A nor decreased p21 expression (Fig. 1 \& 2). Together, this suggests that p16 expression is not sufficient but is necessary to induce transcription of the SASP.

One important question that remains is how does p16 loss mechanistically affect SASP gene expression? p16 is a critical cell cycle regulator, and its suppression both enhances proliferation and allows for senescence bypass [8-10, 12, 70, 71]. Decreased LMNB1 expression plays an important role in the establishment of the SASP [72]. Recent publications demonstrate that decreased expression of $L M N B 1$ and consequential decrease of nuclear integrity leads to the accumulation of CCFs that in turn activate the cGAS-STING signaling pathway to drive the SASP [35-37, 73, 74]. Importantly, we found that knockdown of p16 decreased SASP gene expression, which was not a consequence of increased LMNB1 expression (Fig. 2). Therefore, this is likely not due to downregulation of cGAS-STING signaling, which is directly affected by LMNB1 and nuclear integrity [35]. Notably, we found that patient tumors with low p16 expression have decreased cytosolic DNA sensing pathway signaling in comparison with p16 high tumors (Fig. 4C); however, no correlation was found between CDKN2A and LMNB1 mRNA expression (Fig. 
4D), suggesting that additional mechanisms are at play in tumors with low $\mathrm{p} 16$ expression. Loss of $C D K N 2 A$ is often due to deletion or hypermethylation of the locus [66]. Interestingly, previous work has suggested that melanomas with low MTAP have decreased cGAS-STING signaling [75], and MTAP is often co-deleted/silenced with CDKN2A [76]. Therefore, multiple mechanisms may exist in tumors with loss of this locus to suppress SASP gene expression and/or modulate the tumor microenvironment. Additionally, p16 can negatively regulate TP53 (encoding for p53) at the transcriptional level and also at the protein level by increasing Mdm2-dependent degradation of p53 $[77,78]$. As p53 is a negative regulator of the SASP [79], it is possible that the observed decrease in SASP expression upon p16 suppression is due to negative regulation of p53. Future studies are needed to determine the exact mechanism by which p16 suppression decreases SASP gene expression.

We and others have shown that in addition to its canonical role regulating cell cycle progression though the RB pathway, p16 has non-canonical activities that regulate other important aspects of cellular physiology such as nucleotide metabolism, reactive oxygen species, and miRNAs among others $[80,81]$. In this regard, some studies have found that pharmacological inhibition of canonical downstream targets of $\mathrm{p} 16$, namely CDK4/6, leads to an induction of SASP factors, recruitment of antitumor immune cells, and senescence [82-85], suggesting that $\mathrm{p} 16$ regulation of SASP expression and the tumor immune microenvironment may be due to non-canonical (RBindependent) mechanisms. On the contrary, other authors suggest that inhibition of CDK4/6 alone does not induce a SASP and immunologic responses [86]. Additional studies are needed to delineate the exact mechanism whereby suppression of $p 16$ decreases SASP and verify that this is in an RB-independent, non-canonical pathway. 
Our data suggest that melanoma, pancreatic adenocarcinoma, and colorectal adenocarcinoma tumors with low CDKN2A expression have decreased SASP factor expression (Fig. 4). Importantly, our study shows that low $C D K N 2 A$ expression correlates with downregulation of a distinctive SASP profile depending on the tissue of origin (Fig. 4B). This observation is consistent with previous studies suggesting that the SASP composition is temporally dynamic and contextand senescence inducer-dependent $[53,54,87]$. Characterization of the different SASP profiles and their unique dynamics will be critical not only to assess the senescent cell burden, but also to develop specific and personalized senescence- and SASP-targeted therapies. Since suppression of $\mathrm{p} 16$ can lead to senescence bypass and promote tumorigenesis [8-10, 12, 70, 71], obtaining profiles of the SASP factors related to this process may help treat the $\sim 50 \%$ of all human tumors with low p16 expression [58].

It is well-established that the SASP has pleiotropic, context-dependent effects that both promote tumor progression, but also enhance anti-tumor immunity [reviewed in [88]]. For example, IL6 promotes chronic inflammation and tumorigenesis [89]. However, recent studies suggest that IL6 can also enhance anti-tumor immunity by resculpting $\mathrm{T}$ cell-mediated immune responses [89]. Likewise, other SASP factors, such as IL1a, IL1b, and TNF have this dual role where they can both promote inflammation and tumorigenesis or impair malignant transformation of benign nevi [90]. Using data from TCGA, we found that melanoma, pancreatic adenocarcinoma, and colorectal adenocarcinoma patients with low CDKN2A expression have a decreased SASP signature as well as decreased Antigen Processing Cross Presentation signaling [i.e., the ability of antigen presenting cells to present antigens on major histocompatibility complexes (MHCs) to T-cells]. Consistent with our observation, it has been shown that OIS primary human melanocytes upregulate the $\mathrm{MHC}$ class II apparatus to induce T-cell proliferation and that melanoma patients that sustain this feature have favorable disease outcome [91]. Additionally, suppression of p16 
activity has been associated with immune deserts, immune escape, and low cytolytic activity in melanoma and pancreatic adenocarcinoma [92-94]. Thus, it is possible that in the context of certain tumor types such as those studied here, the decreased expression of SASP factors observed upon p16 knockdown or in CDKN2A-low patients may contribute to abrogation of senescence surveillance by immune cells [47, 95], thereby promoting tumorigenesis. Future experiments will determine whether suppression of p16 leads to decreased immune surveillance and the mechanism whereby this occurs.

Although loss of $\mathrm{p} 16$ is one of the most common events in cancer ( $50 \%$ of all human cancers), there are currently no approved targeted therapies [80]. Additionally, we and others have shown that suppression of $\mathrm{p} 16$ has roles outside the cell cycle that would not be affected with current therapies undergoing clinical trials targeting CDK4/6 [80]. Therefore, finding downstream targetable pathways may be beneficial for this large subset of patients. For instance, we previously showed that inhibition of nucleotide metabolism through suppression of mTORC1 or the pentose phosphate pathway enzyme Ribose 5-Phosphate Isomerase A (RPIA) induces senescence specifically in p16-low cancers [8]. Here we found that suppression of p16 leads to decreased SASP expression. Therefore, induction of senescence in p16-low cancers may be a valuable strategy to inhibit the cell cycle while not activating the potential deleterious effects of the SASP.

In summary, we found that suppression of p16 decreases expression of SASP genes IL6 and CXCL8, which cannot be explained by inhibition of senescence. We found that this phenomenon also occurs in p16-wildtype tumor cells upon p16 knockdown, and there is a decrease in the SASP gene signature in multiple tumor types that is associated with low p16 expression. Understanding 
bioRxiv preprint doi: https://doi.org/10.1101/2020.08.19.257717; this version posted August 19, 2020. The copyright holder for this preprint (which was not certified by peer review) is the author/funder, who has granted bioRxiv a license to display the preprint in perpetuity. It is made available under aCC-BY-NC-ND 4.0 International license.

whether p16 regulates SASP expression is critical to understand the complex relationship between cellular senescence, the immune system, and the cell cycle, three key players in cancer regulation. 


\section{Methods}

$\underline{\text { Cell lines }}$

Normal diploid IMR90 human fibroblasts were obtained from ATCC (CCL-186) and cultured according to the ATCC protocol in DMEM (Corning, cat\#10-017-CV) supplemented with 5\% FBS (VWR, cat\#97068-085), L-glutamine (Corning, cat\#25-015-Cl), non-essential amino acids (Corning, cat\#25-025-Cl), sodium pyruvate (Corning, cat\#25-000-Cl), and sodium bicarbonate (Corning, cat\#25-035-Cl). Cells were cultured under physiological oxygen conditions $\left(2 \% \mathrm{O}_{2}\right)$ and $5 \% \mathrm{CO}_{2}$. Normal skin fibroblasts derived from a melanoma patient $\mathrm{Hs} 895$.Sk were obtained from ATCC (CRL-7636) and cultured in DMEM (Corning, cat\#10-013-CV) supplemented with 10\% FBS (VWR, cat\#97068-085). Experiments were performed on IMR90 between population doubling \#25-35 and in Hs 895.Sk between population doubling \#4-10. Melanoma cell lines SKMel28, Hs 600.T and RPMI-7951, were obtained from ATCC (HTB-72, CRL-7368, and HTB-66, respectively). SKMel28 and $\mathrm{Hs} 600 . \mathrm{T}$ as well as the lentiviral and retroviral packaging cells (293FT and Phoenix, respectively) were cultured in DMEM (Corning, cat\#10-013-CV) supplemented with 10\% FBS, while RPMI-7951 were cultured in EMEM (ATCC, cat\#30-2003) supplemented with $10 \%$ FBS. Hs 895 .Sk and cancer cell lines were cultured under $5 \% \mathrm{CO}_{2}$. All cell lines were cultured in MycoZap (Lonza, cat\#VZA-2032) and were tested for mycoplasma every two months as described in [96]. All tumor cell lines express wildtype CDKN2A according to TCGA $[97,98]$.

Lentiviral and retroviral packaging and infection

pBABE BRAF ${ }^{\mathrm{V} 600 \mathrm{E}}$ (Addgene cat\#15269), pBABE HRAS ${ }^{\mathrm{G} 12 \mathrm{~V}}$ (Addgene cat\#9051), and pBABE empty control (Addgene cat\#1764) vectors were packaged into retroviral particles using the BBS/calcium chloride method as previously described in [8]. pLKO.1-shp16 (Sigma-Aldrich, 
TRCN0000010482) and pLKO.1-shGFP control (Addgene, cat\#30323) vectors were packaged using the ViraPower Kit (Invitrogen, cat\# K497500). Experimental timelines for IMR90 and Hs 895.Sk are delineated in Fig. 1A\&2A. Briefly, cells were infected with pBABE control, pBABE $\mathrm{BRAF}^{\mathrm{V} 600 \mathrm{E}}$, or pBABE HRAS ${ }^{\mathrm{G} 12 \mathrm{~V}}$ retroviral particles, and 24 hours later cells were infected with a second round of corresponding retroviral particles. Cells were infected with pLKO.1-shp16 or pLKO.1-shGFP when indicated in Fig. 1A\&2A. Cells were selected with $1 \mu \mathrm{g} / \mathrm{mL}$ puromycin for single infections or $3 \mu \mathrm{g} / \mathrm{mL}$ for double infections until the end of the experimental procedure.

\section{$\underline{\mathrm{RT}-\mathrm{qPCR}}$}

Total RNA was extracted from cells with Trizol (Ambion, cat\#15596018) and DNase treated, cleaned, and concentrated using Zymo columns (Zymo Research, cat\#R1013) following the manufacturer's instructions. Optical density values for RNA were measured using NanoDrop One (Thermo Scientific) to confirm an A260 and A280 ratios above 1.9. Relative expression of IL6, CXCL8, and LMNB1 were analyzed using the QuantStudio 3 Real-Time PCR System (Thermo Fisher Scientific) with clear 96-well plates (Greiner Bio-One, cat\#652240). Primers were designed using the Integrated DNA Technologies (IDT) web tool (IL6: forward 5'GCCCAGCTATGAACTCCTTCT -3' and reverse 5'- GAAGGCAGCAGGCAACAC -3', CXCL8: forward 5'- AGACAGCAGAGCACACAAGC -3' and reverse 5'- ATGGTTCCTTCCGGTGGT -3', LMNB1: forward 5' -GAGAAGGCTCTGCACTGTATAC $\quad-3$ ' and reverse 5'TGGAGTGGTTGTTGAGGAAG -3', MRPL19: forward 5'- CAGTTTCTGGGGATTTGCAT -3' and reverse 5'- TATTCAGGAAGGGCATCTCG $\quad$-3', PSMC4: forward 5'TGTTGGCAAAGGCGGTGGCA -3' and reverse 5'- TCTCTTGGTGGCGATGGCAT -3' and PUM1: forward 5'- CGGTCGTCCTGAGGATAAAA -3 ' and reverse 5'CGTACGTGAGGCGTGAGTAA -3'). A total of 25ng of RNA was used for One-Step qPCR (Quanta BioSciences, cat\# 95089-200) following the manufacturer's instructions in a final volume 
of $10 \mathrm{uL}$. Conditions for amplification were: $10 \mathrm{~min}$ at $48^{\circ} \mathrm{C}, 5 \mathrm{~min}$ at $95^{\circ} \mathrm{C}, 40$ cycles of $10 \mathrm{sec}$ at $95^{\circ} \mathrm{C}$ and $7 \mathrm{sec}$ at $62^{\circ} \mathrm{C}$. The assay ended with a melting curve program: $15 \mathrm{sec}$ at $95^{\circ} \mathrm{C}, 1 \mathrm{~min}$ at $70^{\circ} \mathrm{C}$, then ramping to $95^{\circ} \mathrm{C}$ while continuously monitoring fluorescence. Each sample was assessed in triplicate. Relative quantification was determined to multiple reference genes (MRPL19, PSMC4 and PUM1) to ensure reproducibility using the delta-delta CT method.

\section{Western blotting}

Cell lysates were collected in 1X sample buffer (2\% SDS, $10 \%$ glycerol, $0.01 \%$ bromophenol blue, 62.5mM Tris, $\mathrm{pH}=6.8,0.1 \mathrm{M} \mathrm{DTT})$ and boiled $\left(10 \mathrm{~min}\right.$, at $\left.95^{\circ} \mathrm{C}\right)$. Protein concentration was determined using Bradford assay (Bio-Rad, cat\#5000006). Proteins were resolved using SDSPAGE gels and transferred to nitrocellulose membranes (GE Healthcare Life Sciences, cat\#10600001) as previously described in [8]. Antibodies used include: anti-BRAF (Santa Cruz Biotechnology, cat\#sc-5284, 1/1000 dilution), anti-RAS (BD Sciences, cat\#610001, 1/1000 dilution), anti-p16 (Abcam, cat\#ab108349, 1/1000 dilution), anti-vinculin (Sigma-Aldrich cat\#V9131, 1/1000 dilution), $\beta$-Actin (Sigma-Aldrich, cat\#A1978, 1/10000 dilution), anti-mouse HRP (Cell Signaling Technology, cat\#cst7076, 1/10000 dilution), and anti-rabbit HRP (Cell Signaling Technology, cat\#cst7074, 1/5000 dilution).

\section{Differential expression analysis}

Preprocessed and processed RNA-Seq data from skin cutaneous melanoma (SKCM), pancreatic adenocarcinoma (PAAD), and colorectal adenocarcinoma (COADREAD) TCGA data were downloaded from BROAD GDAC Firehose on June 22, 2020 [Broad Institute TCGA Genome Data Analysis Center (2016): Firehose 2016_01_28 run. Broad Institute of MIT and Harvard. doi:10.7908/C11G0KM9)]. Processed rnaseqv2 files containing normalized RSEM expression 
values for each gene in each patient were used to determine the first and third quartile of CDKN2A expression for each tumor type separately (Table 1). Quartile values were used to classify patients into low-p16 expression (CDKN2A expression $\left.\leq Q_{1}\right)$ and high-p16 expression (CDKN2A expression $\geq Q_{3}$ ). Differential expression analysis between $\mathrm{p} 16$-low and $\mathrm{p} 16$-hihg patients for each tumor type was performed using the preprocessed raw-counts files in R-CRAN (R-3.6.3) and the DESeq2 package.

\section{Gene Set Enrichment Analysis (GSEA)}

Genes were ranked according to the fold-change and p-value obtained in the differential expression analysis as follows: $-\log _{10}(p$-value $) \times$ sign $\left(\log _{2}\right.$ fold change). Pre-ranked files were built for each tumor type separately in R-CRAN (R-3.6.3) and used to run pre-ranked GSEA (javaGSEA desktop application) for Hallmarks, KEGG and Reactome under predefined parameters (1000 permutations, weighted enrichment statistic, excluding sets larger than 500 and smaller than 15 and using meandiv normalization mode, there were no repeated genes thus collapse mode was not used). Following GSEA documentation, indications terms were considered significant when the FDR adjusted p-value (q-value) was $<0.25$ (http://software.broadinstitute.org/gsea/index.jsp).

\section{$\underline{\text { Statistical Analysis }}$}

GraphPad Prism version 7.0 was used to perform statistical analysis. The level of significance between two groups was assessed with unpaired t test. For data sets with more than two groups, one-way ANOVA followed by Tukey's post hoc test was applied. P-values $<0.05$ were considered significant. Pearson correlation test in GraphPad prism version 7.0 was used to assess the correlation between LMNB1 and CDKN2A. Venny 2.0 tool was used to obtain common 
bioRxiv preprint doi: https://doi.org/10.1101/2020.08.19.257717; this version posted August 19, 2020. The copyright holder for this preprint (which was not certified by peer review) is the author/funder, who has granted bioRxiv a license to display the preprint in perpetuity. It is made available under aCC-BY-NC-ND 4.0 International license.

downregulated genes among tumor types (Fig. 4B and Table S3) as well as common GSEA terms (Table S4). 


\section{Acknowledgments}

We thank Erika Dahl and Drs. Chi-Wei Chen and Naveen Kumar Tangudu for critical reading and editing of this manuscript. We also thank Dr. Gary Nolan from Stanford University for providing with Phoenix packaging cells.

\section{Conflicts of Interest}

The authors declare no conflicts of interest.

\section{Funding}

This work was supported by grants from the National Institutes of Health (F31CA250366 to K.E.L. and R37CA240625 and R00CA194309 to K.M.A.) and a Penn State Cancer Institute Postdoctoral Fellowship (R.B.). 


\section{References}

1. Collado M, Blasco MA and Serrano M. Cellular senescence in cancer and aging. Cell. 2007; 130(2):223-233.

2. Aird KM and Zhang R. Nucleotide metabolism, oncogene-induced senescence and cancer. Cancer letters. 2015; 356(2 Pt A):204-210.

3. Yaswen $P$ and Campisi J. Oncogene-induced senescence pathways weave an intricate tapestry. Cell. 2007; 128(2):233-234.

4. Bringold F and Serrano M. Tumor suppressors and oncogenes in cellular senescence. Exp Gerontol. 2000; 35(3):317-329.

5. Serrano M, Lin AW, McCurrach ME, Beach D and Lowe SW. Oncogenic ras provokes premature cell senescence associated with accumulation of p53 and p16INK4a. Cell. 1997; 88(5):593-602.

6. Stein GH, Drullinger LF, Soulard A and Dulic V. Differential roles for cyclin-dependent kinase inhibitors p21 and p16 in the mechanisms of senescence and differentiation in human fibroblasts. Mol Cell Biol. 1999; 19(3):2109-2117.

7. Sherr CJ. The INK4a/ARF network in tumour suppression. Nature reviews Molecular cell biology. 2001; 2(10):731-737.

8. Buj R, Chen CW, Dahl ES, Leon KE, Kuskovsky R, Maglakelidze N, Navaratnarajah M, Zhang G, Doan MT, Jiang H, Zaleski M, Kutzler L, Lacko H, et al. Suppression of p16 Induces mTORC1-Mediated Nucleotide Metabolic Reprogramming. Cell reports. 2019; 28(8):1971-1980.e1978.

9. Chin L, Pomerantz J, Polsky D, Jacobson M, Cohen C, Cordon-Cardo C, Horner JW, 2nd and DePinho RA. Cooperative effects of INK4a and ras in melanoma susceptibility in vivo. Genes Dev. 1997; 11(21):2822-2834.

10. Dankort D, Filenova E, Collado M, Serrano M, Jones K and McMahon M. A new mouse model to explore the initiation, progression, and therapy of BRAFV600Einduced lung tumors. Genes \& development. 2007; 21(4):379-384.

11. Goel VK, Ibrahim N, Jiang G, Singhal M, Fee S, Flotte T, Westmoreland S, Haluska FS, Hinds PW and Haluska FG. Melanocytic nevus-like hyperplasia and melanoma in transgenic BRAFV600E mice. Oncogene. 2009; 28(23):2289-2298.

12. Haferkamp S, Becker TM, Scurr LL, Kefford RF and Rizos H. p16INK4a-induced senescence is disabled by melanoma-associated mutations. Aging cell. 2008; 7(5):733-745. 
13. Coppe JP, Desprez PY, Krtolica A and Campisi J. The senescence-associated secretory phenotype: the dark side of tumor suppression. Annu Rev Pathol. 2010; 5:99-118.

14. Acosta JC, Banito A, Wuestefeld T, Georgilis A, Janich P, Morton JP, Athineos D, Kang TW, Lasitschka F, Andrulis M, Pascual G, Morris KJ, Khan S, et al. A complex secretory program orchestrated by the inflammasome controls paracrine senescence. Nat Cell Biol. 2013; 15(8):978-990.

15. Baker DJ, Wijshake T, Tchkonia T, LeBrasseur NK, Childs BG, van de Sluis B, Kirkland JL and van Deursen JM. Clearance of p16Ink4a-positive senescent cells delays ageing-associated disorders. Nature. 2011; 479(7372):232-236.

16. Coppe JP, Patil CK, Rodier F, Sun Y, Munoz DP, Goldstein J, Nelson PS, Desprez PY and Campisi J. Senescence-associated secretory phenotypes reveal cellnonautonomous functions of oncogenic RAS and the p53 tumor suppressor. PLoS Biol. 2008; 6(12):2853-2868.

17. Laberge RM, Sun Y, Orjalo AV, Patil CK, Freund A, Zhou L, Curran SC, Davalos AR, Wilson-Edell KA, Liu S, Limbad C, Demaria M, Li P, et al. MTOR regulates the protumorigenic senescence-associated secretory phenotype by promoting IL1A translation. Nat Cell Biol. 2015; 17(8):1049-1061.

18. Takasugi M, Okada R, Takahashi A, Virya Chen D, Watanabe S and Hara E. Small extracellular vesicles secreted from senescent cells promote cancer cell proliferation through EphA2. Nat Commun. 2017; 8:15729.

19. Acosta JC, O'Loghlen A, Banito A, Guijarro MV, Augert A, Raguz S, Fumagalli M, Da Costa M, Brown C, Popov N, Takatsu Y, Melamed J, d'Adda di Fagagna F, et al. Chemokine signaling via the CXCR2 receptor reinforces senescence. Cell. 2008; 133(6):1006-1018.

20. Freund A, Patil CK and Campisi J. p38MAPK is a novel DNA damage responseindependent regulator of the senescence-associated secretory phenotype. EMBO J. 2011; 30(8):1536-1548.

21. Kang C, Xu Q, Martin TD, Li MZ, Demaria M, Aron L, Lu T, Yankner BA, Campisi J and Elledge SJ. The DNA damage response induces inflammation and senescence by inhibiting autophagy of GATA4. Science (New York, NY). 2015; 349(6255):aaa5612.

22. Kuilman T, Michaloglou C, Vredeveld LC, Douma S, van Doorn R, Desmet CJ, Aarden LA, Mooi WJ and Peeper DS. Oncogene-induced senescence relayed by an interleukin-dependent inflammatory network. Cell. 2008; 133(6):1019-1031.

23. Malaquin N, Olivier MA, Martinez A, Nadeau S, Sawchyn C, Coppe JP, Cardin G, Mallette FA, Campisi J and Rodier F. Non-canonical ATM/MRN activities temporally define the senescence secretory program. EMBO Rep. 2020:e50718. 
24. Rodier F, Coppe JP, Patil CK, Hoeijmakers WA, Munoz DP, Raza SR, Freund A, Campeau E, Davalos AR and Campisi J. Persistent DNA damage signalling triggers senescence-associated inflammatory cytokine secretion. Nature cell biology. 2009; 11(8):973-979.

25. Zhao J, Zhang L, Lu A, Han Y, Colangelo D, Bukata C, Scibetta A, Yousefzadeh MJ, Li X, Gurkar AU, McGowan SJ, Angelini L, O'Kelly R, et al. ATM is a key driver of NFkappaB-dependent DNA-damage-induced senescence, stem cell dysfunction and aging. Aging (Albany NY). 2020; 12(6):4688-4710.

26. Aird KM, Iwasaki O, Kossenkov AV, Tanizawa H, Fatkhutdinov N, Bitler BG, Le L, Alicea G, Yang TL, Johnson FB, Noma KI and Zhang R. HMGB2 orchestrates the chromatin landscape of senescence-associated secretory phenotype gene loci. J Cell Biol. 2016; 215(3):325-334.

27. Capell BC, Drake AM, Zhu J, Shah PP, Dou Z, Dorsey J, Simola DF, Donahue G, Sammons M, Rai TS, Natale C, Ridky TW, Adams PD, et al. MLL1 is essential for the senescence-associated secretory phenotype. Genes \& development. 2016; 30(3):321-336.

28. Chen H, Ruiz PD, McKimpson WM, Novikov L, Kitsis RN and Gamble MJ. MacroH2A1 and ATM Play Opposing Roles in Paracrine Senescence and the SenescenceAssociated Secretory Phenotype. Mol Cell. 2015; 59(5):719-731.

29. Hayakawa T, Iwai M, Aoki S, Takimoto K, Maruyama M, Maruyama W and Motoyama N. SIRT1 suppresses the senescence-associated secretory phenotype through epigenetic gene regulation. PLoS One. 2015; 10(1):e0116480.

30. Leon KE and Aird KM. Jumonji C Demethylases in Cellular Senescence. Genes (Basel). 2019; 10(1).

31.Zhang B, Long Q, Wu S, Song S, Xu Q, Han L, Qian M, Ren X, Jiang J, Fu Q, Guo J, Zhang X, Chang X, et al. KDM4 Orchestrates Epigenomic Remodeling of Senescent Cells and Potentiates the Senescence-Associated Secretory Phenotype. bioRxiv. 2020:2020.2008.2003.235465.

32. Herranz N, Gallage S, Mellone M, Wuestefeld T, Klotz S, Hanley CJ, Raguz S, Acosta JC, Innes AJ, Banito A, Georgilis A, Montoya A, Wolter K, et al. mTOR regulates MAPKAPK2 translation to control the senescence-associated secretory phenotype. Nat Cell Biol. 2015; 17(9):1205-1217.

33. Freund A, Laberge RM, Demaria M and Campisi J. Lamin B1 loss is a senescenceassociated biomarker. Molecular biology of the cell. 2012; 23(11):2066-2075.

34. Shimi T, Butin-Israeli V, Adam SA, Hamanaka RB, Goldman AE, Lucas CA, Shumaker DK, Kosak ST, Chandel NS and Goldman RD. The role of nuclear lamin B1 in cell proliferation and senescence. Genes \& development. 2011; 25(24):2579-2593. 
35. Dou Z, Ghosh K, Vizioli MG, Zhu J, Sen P, Wangensteen KJ, Simithy J, Lan Y, Lin Y, Zhou Z, Capell BC, Xu C, Xu M, et al. Cytoplasmic chromatin triggers inflammation in senescence and cancer. Nature. 2017; 550(7676):402-406.

36. Ivanov A, Pawlikowski J, Manoharan I, van Tuyn J, Nelson DM, Rai TS, Shah PP, Hewitt G, Korolchuk VI, Passos JF, Wu H, Berger SL and Adams PD. Lysosomemediated processing of chromatin in senescence. J Cell Biol. 2013; 202(1):129-143.

37. Gluck S, Guey B, Gulen MF, Wolter K, Kang TW, Schmacke NA, Bridgeman A, Rehwinkel J, Zender $L$ and Ablasser A. Innate immune sensing of cytosolic chromatin fragments through cGAS promotes senescence. Nat Cell Biol. 2017; 19(9):10611070.

38. Yang $H$, Wang $H$, Ren J, Chen $Q$ and Chen ZJ. cGAS is essential for cellular senescence. Proc Natl Acad Sci U S A. 2017; 114(23):E4612-E4620.

39. Fane $M$ and Weeraratna AT. How the ageing microenvironment influences tumour progression. Nat Rev Cancer. 2020; 20(2):89-106.

40. Da Silva-Alvarez S, Guerra-Varela J, Sobrido-Camean D, Quelle A, Barreiro-Iglesias $A$, Sanchez $L$ and Collado $M$. Cell senescence contributes to tissue regeneration in zebrafish. Aging Cell. 2020; 19(1):e13052.

41. Demaria M, Ohtani N, Youssef SA, Rodier F, Toussaint W, Mitchell JR, Laberge RM, Vijg J, Van Steeg H, Dolle ME, Hoeijmakers JH, de Bruin A, Hara E, et al. An essential role for senescent cells in optimal wound healing through secretion of PDGF-AA. Developmental cell. 2014; 31(6):722-733.

42. Yun $\mathrm{MH}$, Davaapil $\mathrm{H}$ and Brockes JP. Recurrent turnover of senescent cells during regeneration of a complex structure. Elife. 2015; 4.

43. Munoz-Espin D, Canamero M, Maraver A, Gomez-Lopez G, Contreras J, MurilloCuesta S, Rodriguez-Baeza A, Varela-Nieto I, Ruberte J, Collado M and Serrano M. Programmed cell senescence during mammalian embryonic development. Cell. 2013; 155(5):1104-1118.

44. Storer M, Mas A, Robert-Moreno A, Pecoraro M, Ortells MC, Di Giacomo V, Yosef R, Pilpel N, Krizhanovsky V, Sharpe J and Keyes WM. Senescence is a developmental mechanism that contributes to embryonic growth and patterning. Cell. 2013; 155(5):1119-1130.

45. Eggert T, Wolter K, Ji J, Ma C, Yevsa T, Klotz S, Medina-Echeverz J, Longerich T, Forgues M, Reisinger F, Heikenwalder M, Wang XW, Zender L, et al. Distinct Functions of Senescence-Associated Immune Responses in Liver Tumor Surveillance and Tumor Progression. Cancer Cell. 2016; 30(4):533-547. 
46. Iannello A, Thompson TW, Ardolino M, Lowe SW and Raulet DH. p53-dependent chemokine production by senescent tumor cells supports NKG2D-dependent tumor elimination by natural killer cells. J Exp Med. 2013; 210(10):2057-2069.

47. Kang TW, Yevsa T, Woller N, Hoenicke L, Wuestefeld T, Dauch D, Hohmeyer A, Gereke M, Rudalska R, Potapova A, Iken M, Vucur M, Weiss S, et al. Senescence surveillance of pre-malignant hepatocytes limits liver cancer development. Nature. 2011; 479(7374):547-551.

48. Bavik C, Coleman I, Dean JP, Knudsen B, Plymate S and Nelson PS. The gene expression program of prostate fibroblast senescence modulates neoplastic epithelial cell proliferation through paracrine mechanisms. Cancer Res. 2006; 66(2):794-802.

49. Canino C, Mori F, Cambria A, Diamantini A, Germoni S, Alessandrini G, Borsellino G, Galati R, Battistini L, Blandino R, Facciolo F, Citro G, Strano S, et al. SASP mediates chemoresistance and tumor-initiating-activity of mesothelioma cells. Oncogene. 2012; 31(26):3148-3163.

50. Coppe JP, Kauser K, Campisi J and Beausejour CM. Secretion of vascular endothelial growth factor by primary human fibroblasts at senescence. The Journal of biological chemistry. 2006; 281(40):29568-29574.

51. Yang F, Tuxhorn JA, Ressler SJ, McAlhany SJ, Dang TD and Rowley DR. Stromal expression of connective tissue growth factor promotes angiogenesis and prostate cancer tumorigenesis. Cancer Res. 2005; 65(19):8887-8895.

52. Yoshimoto S, Loo TM, Atarashi K, Kanda H, Sato S, Oyadomari S, Iwakura Y, Oshima K, Morita H, Hattori M, Honda K, Ishikawa $Y$, Hara E, et al. Obesity-induced gut microbial metabolite promotes liver cancer through senescence secretome. Nature. 2013; 499(7456):97-101.

53. Basisty N, Kale A, Jeon OH, Kuehnemann C, Payne T, Rao C, Holtz A, Shah S, Sharma V, Ferrucci L, Campisi J and Schilling B. A proteomic atlas of senescenceassociated secretomes for aging biomarker development. PLoS Biol. 2020; 18(1):e3000599.

54. Hernandez-Segura A, de Jong TV, Melov S, Guryev V, Campisi J and Demaria M. Unmasking Transcriptional Heterogeneity in Senescent Cells. Curr Biol. 2017; 27(17):2652-2660 e2654.

55. Toso A, Revandkar A, Di Mitri D, Guccini I, Proietti M, Sarti M, Pinton S, Zhang J, Kalathur M, Civenni G, Jarrossay D, Montani E, Marini C, et al. Enhancing chemotherapy efficacy in Pten-deficient prostate tumors by activating the senescence-associated antitumor immunity. Cell Rep. 2014; 9(1):75-89.

56. Wang B, Kohli J and Demaria M. Senescent Cells in Cancer Therapy: Friends or Foes? Trends Cancer. 2020. 
57. Rao SG and Jackson JG. SASP: Tumor Suppressor or Promoter? Yes! Trends in cancer. 2016; 2(11):676-687.

58. Romagosa C, Simonetti S, Lopez-Vicente L, Mazo A, Lleonart ME, Castellvi J and Ramon y Cajal S. p16(Ink4a) overexpression in cancer: a tumor suppressor gene associated with senescence and high-grade tumors. Oncogene. 2011; 30(18):20872097.

59. Coppe JP, Rodier F, Patil CK, Freund A, Desprez PY and Campisi J. Tumor suppressor and aging biomarker p16(INK4a) induces cellular senescence without the associated inflammatory secretory phenotype. J Biol Chem. 2011; 286(42):3639636403.

60. Ortiz-Montero P, Londono-Vallejo A and Vernot JP. Senescence-associated IL-6 and IL-8 cytokines induce a self- and cross-reinforced senescence/inflammatory milieu strengthening tumorigenic capabilities in the MCF-7 breast cancer cell line. Cell Commun Signal. 2017; 15(1):17.

61. Zhu J, Woods D, McMahon M and Bishop JM. Senescence of human fibroblasts induced by oncogenic Raf. Genes Dev. 1998; 12(19):2997-3007.

62. Chakravarti A, Heydon K, Wu CL, Hammond E, Pollack A, Roach M, Wolkov H, Okunieff P, Cox J, Fontanesi J, Abrams R, Pilepich M, Shipley W, et al. Loss of p16 expression is of prognostic significance in locally advanced prostate cancer: an analysis from the Radiation Therapy Oncology Group protocol 86-10. J Clin Oncol. 2003; 21(17):3328-3334.

63. Straume O, Sviland L and Akslen LA. Loss of nuclear p16 protein expression correlates with increased tumor cell proliferation (Ki-67) and poor prognosis in patients with vertical growth phase melanoma. Clin Cancer Res. 2000; 6(5):1845-1853.

64. Weinberger PM, Yu Z, Haffty BG, Kowalski D, Harigopal M, Sasaki C, Rimm DL and Psyrri A. Prognostic significance of p16 protein levels in oropharyngeal squamous cell cancer. Clin Cancer Res. 2004; 10(17):5684-5691.

65. Witkiewicz AK, Knudsen KE, Dicker AP and Knudsen ES. The meaning of p16(ink4a) expression in tumors: functional significance, clinical associations and future developments. Cell Cycle. 2011; 10(15):2497-2503.

66.Zhao R, Choi BY, Lee MH, Bode AM and Dong Z. Implications of Genetic and Epigenetic Alterations of CDKN2A (p16(INK4a)) in Cancer. EBioMedicine. 2016; 8:3039.

67. Liu JY, Souroullas GP, Diekman BO, Krishnamurthy J, Hall BM, Sorrentino JA, Parker JS, Sessions GA, Gudkov AV and Sharpless NE. Cells exhibiting strong p16 (INK4a) promoter activation in vivo display features of senescence. Proc Natl Acad Sci U S A. 2019; 116(7):2603-2611. 
68. Herranz $\mathrm{N}$ and Gil J. Mechanisms and functions of cellular senescence. J Clin Invest. 2018; 128(4):1238-1246.

69. Meyer P, Maity P, Burkovski A, Schwab J, Mussel C, Singh K, Ferreira FF, Krug L, Maier HJ, Wlaschek M, Wirth T, Kestler HA and Scharffetter-Kochanek K. A model of the onset of the senescence associated secretory phenotype after DNA damage induced senescence. PLoS Comput Biol. 2017; 13(12):e1005741.

70.Damsky W, Micevic G, Meeth K, Muthusamy V, Curley DP, Santhanakrishnan M, Erdelyi I, Platt JT, Huang L, Theodosakis N, Zaidi MR, Tighe S, Davies MA, et al. mTORC1 activation blocks BrafV600E-induced growth arrest but is insufficient for melanoma formation. Cancer cell. 2015; 27(1):41-56.

71. Krimpenfort P, Quon KC, Mooi WJ, Loonstra A and Berns A. Loss of p16Ink4a confers susceptibility to metastatic melanoma in mice. Nature. 2001; 413(6851):83-86.

72. Shah PP, Donahue G, Otte GL, Capell BC, Nelson DM, Cao K, Aggarwala V, Cruickshanks HA, Rai TS, McBryan T, Gregory BD, Adams PD and Berger SL. Lamin B1 depletion in senescent cells triggers large-scale changes in gene expression and the chromatin landscape. Genes Dev. 2013; 27(16):1787-1799.

73. Hari P, Millar FR, Tarrats N, Birch J, Quintanilla A, Rink CJ, Fernandez-Duran I, Muir M, Finch AJ, Brunton VG, Passos JF, Morton JP, Boulter L, et al. The innate immune sensor Toll-like receptor 2 controls the senescence-associated secretory phenotype. Sci Adv. 2019; 5(6):eaaw0254.

74. Takahashi A, Loo TM, Okada R, Kamachi F, Watanabe Y, Wakita M, Watanabe S, Kawamoto S, Miyata K, Barber GN, Ohtani N and Hara E. Downregulation of cytoplasmic DNases is implicated in cytoplasmic DNA accumulation and SASP in senescent cells. Nat Commun. 2018; 9(1):1249.

75. Kim H, Kim H, Feng Y, Li Y, Tamiya H, Tocci S and Ronai ZA. PRMT5 control of cGAS/STING and NLRC5 pathways defines melanoma response to antitumor immunity. Sci Transl Med. 2020; 12(551).

76. Zhang H, Chen ZH and Savarese TM. Codeletion of the genes for p16INK4, methylthioadenosine phosphorylase, interferon-alpha1, interferon-beta1, and other 9p21 markers in human malignant cell lines. Cancer Genet Cytogenet. 1996; 86(1):2228.

77. Huschtscha LI, Moore JD, Noble JR, Campbell HG, Royds JA, Braithwaite AW and Reddel RR. Normal human mammary epithelial cells proliferate rapidly in the presence of elevated levels of the tumor suppressors p53 and p21(WAF1/CIP1). J Cell Sci. 2009; 122(Pt 16):2989-2995.

78. Kubbutat $\mathrm{MH}$, Jones $\mathrm{SN}$ and Vousden $\mathrm{KH}$. Regulation of p53 stability by Mdm2. Nature. 1997; 387(6630):299-303. 
79. Wiley CD, Schaum N, Alimirah F, Lopez-Dominguez JA, Orjalo AV, Scott G, Desprez PY, Benz C, Davalos AR and Campisi J. Small-molecule MDM2 antagonists attenuate the senescence-associated secretory phenotype. Sci Rep. 2018; 8(1):2410.

80.Buj R and Aird KM. p16: cycling off the beaten path. Mol Cell Oncol. 2019; 6(6):e1677140.

81. Mirzayans R, Andrais B, Hansen G and Murray D. Role of p16(INK4A) in Replicative Senescence and DNA Damage-Induced Premature Senescence in p53-Deficient Human Cells. Biochem Res Int. 2012; 2012:951574.

82. Birnhuber A, Egemnazarov B, Biasin V, Bonyadi Rad E, Wygrecka M, Olschewski H, Kwapiszewska G and Marsh LM. CDK4/6 inhibition enhances pulmonary inflammatory infiltration in bleomycin-induced lung fibrosis. Respir Res. 2020; 21(1):167.

83. Goel S, DeCristo MJ, Watt AC, BrinJones H, Sceneay J, Li BB, Khan N, Ubellacker JM, Xie S, Metzger-Filho O, Hoog J, Ellis MJ, Ma CX, et al. CDK4/6 inhibition triggers anti-tumour immunity. Nature. 2017; 548(7668):471-475.

84. Guan X, LaPak KM, Hennessey RC, Yu CY, Shakya R, Zhang J and Burd CE. Stromal Senescence By Prolonged CDK4/6 Inhibition Potentiates Tumor Growth. Mol Cancer Res. 2017; 15(3):237-249.

85. Yoshida A, Lee EK and Diehl JA. Induction of Therapeutic Senescence in Vemurafenib-Resistant Melanoma by Extended Inhibition of CDK4/6. Cancer Res. 2016; 76(10):2990-3002.

86. Ruscetti M, Leibold J, Bott MJ, Fennell M, Kulick A, Salgado NR, Chen CC, Ho YJ, Sanchez-Rivera FJ, Feucht J, Baslan T, Tian S, Chen HA, et al. NK cell-mediated cytotoxicity contributes to tumor control by a cytostatic drug combination. Science. 2018; 362(6421):1416-1422.

87. Hoare M, Ito Y, Kang TW, Weekes MP, Matheson NJ, Patten DA, Shetty S, Parry AJ, Menon S, Salama R, Antrobus R, Tomimatsu K, Howat W, et al. NOTCH1 mediates a switch between two distinct secretomes during senescence. Nat Cell Biol. 2016; 18(9):979-992.

88. Faget DV, Ren $Q$ and Stewart SA. Unmasking senescence: context-dependent effects of SASP in cancer. Nat Rev Cancer. 2019; 19(8):439-453.

89. Fisher DT, Appenheimer MM and Evans SS. The two faces of IL-6 in the tumor microenvironment. Semin Immunol. 2014; 26(1):38-47.

90. Ahmed AA, Nordlind K, Hedblad M, Lagerholm B, Schultzberg M and Liden S. Interleukin (IL)-1 alpha- and -1 beta-, IL-6-, and tumor necrosis factor-alpha-like immunoreactivities in human common and dysplastic nevocellular nevi and malignant melanoma. Am J Dermatopathol. 1995; 17(3):222-229. 
91. van Tuyn J, Jaber-Hijazi F, MacKenzie D, Cole JJ, Mann E, Pawlikowski JS, Rai TS, Nelson DM, McBryan T, Ivanov A, Blyth K, Wu H, Milling S, et al. OncogeneExpressing Senescent Melanocytes Up-Regulate MHC Class II, a Candidate Melanoma Suppressor Function. The Journal of investigative dermatology. 2017; 137(10):2197-2207.

92. Balli D, Rech AJ, Stanger BZ and Vonderheide RH. Immune Cytolytic Activity Stratifies Molecular Subsets of Human Pancreatic Cancer. Clin Cancer Res. 2017; 23(12):3129-3138.

93. Morrison C, Pabla S, Conroy JM, Nesline MK, Glenn ST, Dressman D, PapanicolauSengos A, Burgher B, Andreas J, Giamo V, Qin M, Wang Y, Lenzo FL, et al. Predicting response to checkpoint inhibitors in melanoma beyond PD-L1 and mutational burden. J Immunother Cancer. 2018; 6(1):32.

94. Wartenberg M, Cibin S, Zlobec I, Vassella E, Eppenberger-Castori S, Terracciano L, Eichmann MD, Worni M, Gloor B, Perren A and Karamitopoulou E. Integrated Genomic and Immunophenotypic Classification of Pancreatic Cancer Reveals Three Distinct Subtypes with Prognostic/Predictive Significance. Clin Cancer Res. 2018; 24(18):4444-4454.

95. Hoenicke $\mathrm{L}$ and Zender $\mathrm{L}$. Immune surveillance of senescent cells--biological significance in cancer- and non-cancer pathologies. Carcinogenesis. 2012; 33(6):1123-1126.

96. Uphoff CC and Drexler HG. Detection of mycoplasma contaminations. Methods in molecular biology (Clifton, NJ). 2005; 290:13-23.

97. Cerami E, Gao J, Dogrusoz U, Gross BE, Sumer SO, Aksoy BA, Jacobsen A, Byrne CJ, Heuer ML, Larsson E, Antipin Y, Reva B, Goldberg AP, et al. The cBio cancer genomics portal: an open platform for exploring multidimensional cancer genomics data. Cancer discovery. 2012; 2(5):401-404.

98. Gao J, Aksoy BA, Dogrusoz U, Dresdner G, Gross B, Sumer SO, Sun Y, Jacobsen A, Sinha R, Larsson E, Cerami E, Sander C and Schultz N. Integrative analysis of complex cancer genomics and clinical profiles using the cBioPortal. Sci Signal. 2013; 6(269):pl1. 


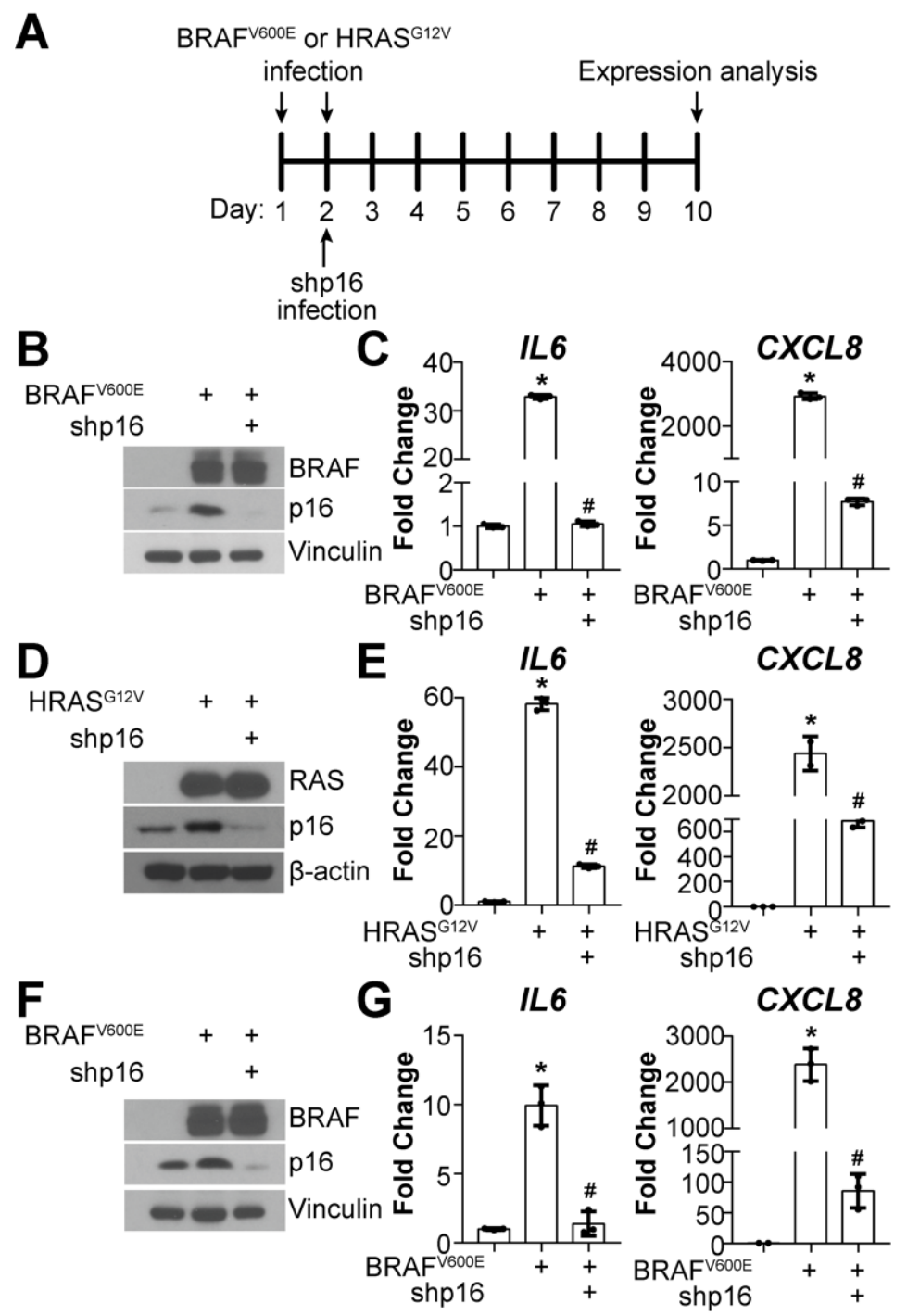

Figure 1. Knockdown of p16 decreases IL6 and CXCL8 expression in OIS cells. (A) Schematic of infection of cells. (B-C) IMR90 cells expressing BRAF ${ }^{\mathrm{V} 600 \mathrm{E}}$ alone or in combination with shRNA targeting p16 (shp16). (B) Immunoblot of the indicated proteins. (C) IL6 and CXCL8 mRNA expression. (D-E) IMR90 cells expressing HRAS ${ }^{\mathrm{G} 12 \mathrm{~V}}$ alone or in combination with shp16. (D) Immunoblot of the indicated proteins. (E) IL6 and CXCL8 mRNA expression. (F-G) Hs 895.SK cells expressing BRAF ${ }^{\mathrm{V} 600 \mathrm{E}}$ alone or in combination with shp16. (F) Immunoblot of the indicated proteins. (G) IL6 and CXCL8 mRNA expression. Expression data show fold change relative to control mean +/- SD. Expression of target genes was normalized against multiple reference genes. Data normalized against MRPL9 is represented. ${ }^{*} \mathrm{p}<0.05$ vs. control; $\# p<0.05$ vs. $\mathrm{BRAF}^{\mathrm{V} 600 \mathrm{E}}$ or HRAS ${ }^{\mathrm{G} 12 \mathrm{~V}}$ alone. 


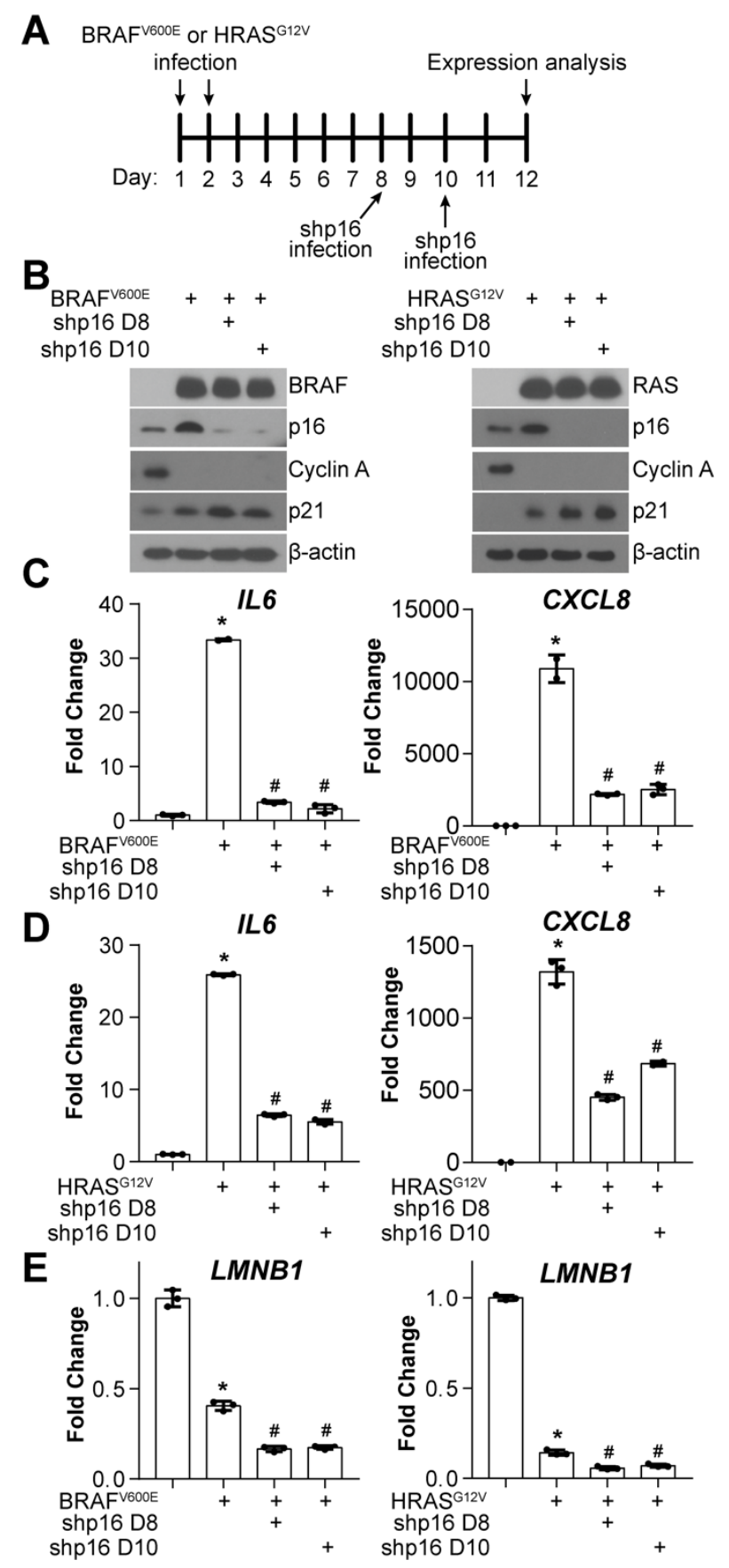

Figure 2. Knockdown of p16 at later timepoints decreases IL6 and CXCL8, while not increasing $L M N B 1$ expression in OIS cells. (A) Schematic of infection of cells. (B-E) IMR90 cells expressing $\mathrm{BRAF}^{\mathrm{V} 600 \mathrm{E}}$ or $\mathrm{HRAS}^{\mathrm{G} 12 \mathrm{~V}}$ alone or in combination with shRNA targeting p16 (shp16) at the indicated time points (D8 = day 8; D10 = day 10). (B) Immunoblot of the indicated proteins. (C) IL6 and CXCL8 mRNA expression in the BRAF ${ }^{\mathrm{V} 600 \mathrm{E}}$ model. (D) IL6 and CXCL8 mRNA expression in the HRAS ${ }^{\mathrm{G} 12 \mathrm{~V}}$ model. (E) $L M N B 1 \mathrm{mRNA}$ expression. Expression data show fold change relative to control mean $+/-$ SD. Expression of target genes was normalized against multiple reference genes. Data normalized against MRPL19 is represented. ${ }^{*} p<0.05$ vs. control; $\# p<0.05$ vs. BRAF ${ }^{\mathrm{V} 600 \mathrm{E}}$ or $\mathrm{HRAS}^{\mathrm{G} 12 \mathrm{~V}}$ alone. 


\section{A SKMel28 RPMI-7951 Hs 600T}
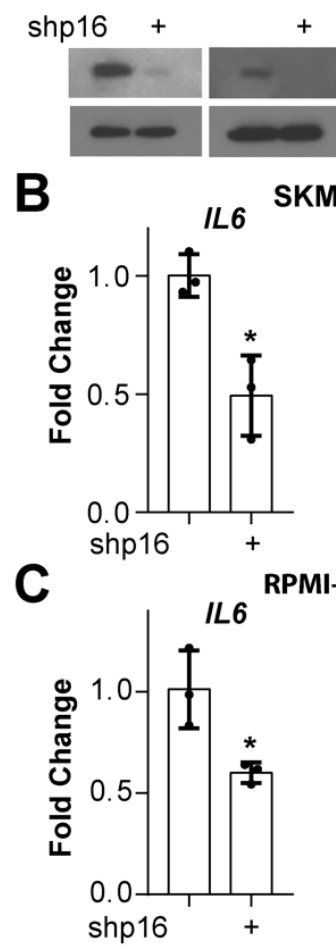

RPMI-7951
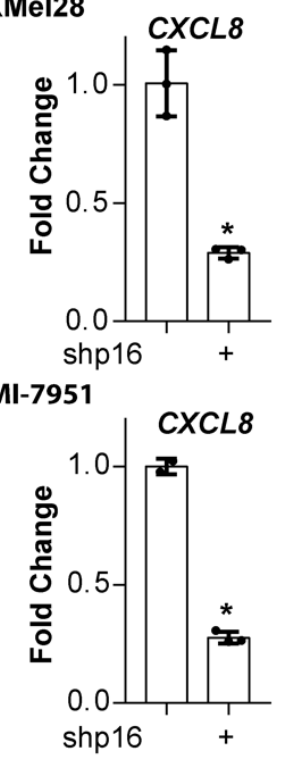

D

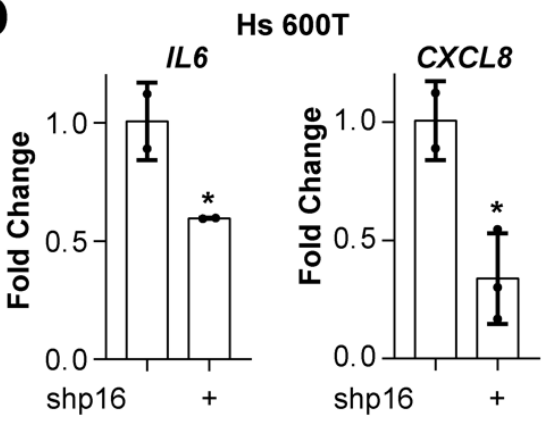

Figure 3. Knockdown of p16 in melanoma cells decreases IL6 and CXCL8 expression. The melanoma cell lines SKMel28, RPMI-7951, and Hs 600T expressing wildtype p16 were infected with lentivirus expressing shRNA targeting p16 (shp16). (A) Immunoblot of the indicated proteins. (B) mRNA expression of IL6 and CXCL8 in SKMel28 melanoma cells. (C) mRNA expression of IL6 and CXCL8 in RPMI-7951 melanoma cell lines. (D) mRNA expression of IL6 and CXCL8 in Hs 600T melanoma cell lines. Expression data show fold change relative to control mean $+/$ SD. Expression of target genes was normalized against multiple reference genes. Data normalized against MRPL9 is represented. ${ }^{*} \mathrm{p}<0.05$. 

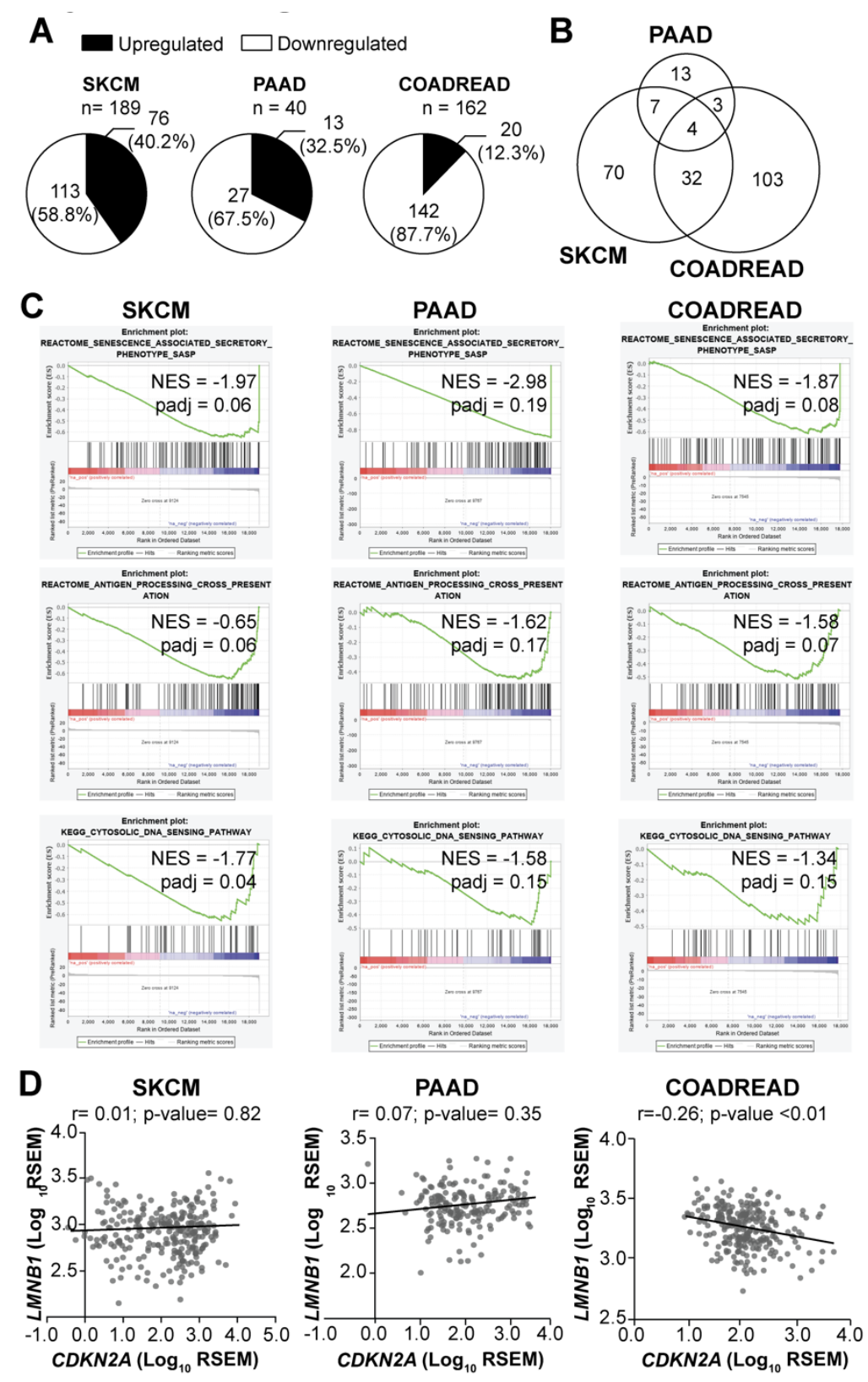

Figure 4. Tumors with low CDKN2A expression have decreased expression of SASP and inflammation-related signatures. (A) Percentage of SASP genes significantly upregulated and downregulated in CDKN2A-low (i.e., p16-low) expressing tumors when compared to CDKN2Ahigh (p16-high) expressing tumors. (B) Cross-comparison of significantly downregulated SASP genes in CDKN2A-low expressing tumors vs. CDKN2A-high expressing tumors in the three tumor types. (C) SASP and inflammation-related common negatively enriched terms among the three studied tumor types in Gene Set Enrichment Analysis (GSEA) between CDKN2A-low and CDKN2A-high expressing tumors. SKCM (skin cutaneous melanoma), PAAD (pancreatic adenocarcinoma), COADREAD (colorectal adenocarcinoma), NES (negative enrichment score). (D) Correlation between CDKN2A and LMNB1 expression for each tumor type. Data are shown as $\log _{10}$ of RSEM. Coefficient of correlation $(R)$ and $p$-value were calculated using Pearson correlation. 
Table 1. Statistics of TCGA data sets

\begin{tabular}{|c|c|c|c|}
\hline & SKCM & PAAD & COADREAD \\
\hline Total cases & 473 & 183 & 82 \\
\hline CDKN2A expression (RSEM) mean & 560.20 & 359.17 & 332.09 \\
\hline CDKN2A expression (RSEM) standard deviation (SD) & 204.21 & 84.31 & 677.87 \\
\hline CDKN2A expression (RSEM) median & 1103.44 & 584.37 & 113.29 \\
\hline$C D K N 2 A$ expression (RSEM) first quartile $\left(Q_{1}\right)$ & 20.21 & 31.92 & 64.39 \\
\hline CDKN2A expression (RSEM) third quartile $\left(Q_{3}\right)$ & 638.01 & 340.72 & 314.50 \\
\hline No. p16-low cases (CDKN2A expression $\left.\leq Q_{1}\right)$ & 119 & 46 & 21 \\
\hline No. p16-high cases (CDKN2A expression $\left.\geq Q_{3}\right)$ & 119 & 46 & 21 \\
\hline
\end{tabular}




\section{Supplemental Materials}

Table S1: 232 total unique SASP genes including soluble factors and exosomes obtained from (Basisty et al., 2020)

Table S2: Differential expression analysis of CDKN2A-low vs. CDKN2A-high tumors obtained from TCGA

Table S3: Cross-comparison of significant downregulated SASP among the three tumor types

Table S4: Cross-comparison of the Gene Set Enrichment Analysis output with negative NES for the tumor types 